\title{
Study of fetal outcome in hypertensive disorders of pregnancy in a tertiary care maternity hospital of Delhi
}

\author{
Kritika Vats*, Mohini Paul
}

Department of Obstetrics and Gynaecology, Kasturba Hospital, Dariyaganj, New Delhi, India

Received: 14 September 2016

Accepted: 26 September 2016

\section{*Correspondence:}

Dr. Kritika Vats,

E-mail: kritika.vats55@gmail.com

Copyright: $\odot$ the author(s), publisher and licensee Medip Academy. This is an open-access article distributed under the terms of the Creative Commons Attribution Non-Commercial License, which permits unrestricted non-commercial use, distribution, and reproduction in any medium, provided the original work is properly cited.

\section{ABSTRACT}

Background: Hypertensive Disorders of Pregnancy is a multifactorial disorder that seriously endangers the safety of the fetus during pregnancy. This study was conducted to study the perinatal outcome of this grave disorder in pregnancy and thus reducing the perinatal morbidity and mortality by prevention and proper management of this condition.

Methods: A "prospective case-control observational study" was conducted in the department of Obstetrics and Gynaecology, Kasturba Hospital, New Delhi.100 pregnant women presenting with hypertension from January 2014 to December 2014 were taken as cases and compared with 100 pregnant women (age and parity matched) in terms of perinatal outcome.

Results: As many as 6 cases with hypertensive disorder of pregnancy had intrauterine death of fetus as compared to 2 intrauterine death of fetus in controls. Birth weight $>2.5 \mathrm{~kg}$ was recorded in $68.4 \%$ of cases while $25.5 \%$ had weight between $1.5 \mathrm{~kg}-2.5 \mathrm{~kg}$ and $6.1 \%$ had weight $<1.5 \mathrm{~kg}$ as compared to controls which had $85 \%>2.5 \mathrm{~kg}, 13 \%$ between $1.5 \mathrm{~kg}-2.5 \mathrm{~kg}$ and $2 \% \mathrm{had}<1.5 \mathrm{~kg}$. The low birth weight in cases was due to IUGR and/or prematurity. $24.49 \%$ of babies of cases with hypertensive disorder of pregnancy had Apgar score $<7$ at 5 minutes after birth as compared to only $14 \%$ of control babies with Apgar $<7.25 .53 \%$ of neonates born to cases were admitted in NICU whereas only $11 \%$ of neonates born to controls were admitted in NICU $(\mathrm{p}=.014) .4 .3 \%$ of neonates born to cases ended up in early neonatal death while there was no early neonatal death among controls.

Conclusions: Thus low birth weight due to prematurity/IUGR and fetal hypoxia were the main reasons for fetal morbidity in hypertensive disorders of pregnancy.

Keywords: Hypertensive disorders of pregnancy, Fetal outcome at birth, IUD, Preterm delivery, Low birth weight, Low APGAR score, Admissions in NICU, Early neonatal deaths

\section{INTRODUCTION}

Hypertensive disorders of pregnancy has remained a significant public threat in both developed and developing countries, contributing globally to maternal and perinatal morbidity and mortality. ${ }^{1,2}$ In India, the incidence of this threatening condition was $5.38 \%$. $^{3}$

Majority of foetal complications occur due to prematurity and hypoxia. ${ }^{4,5}$ Foetal complications are related to the severity of preeclampsia, duration of the disease and degree of proteinuria. ${ }^{6}$ Spasm of the uteroplacental circulation leads to fetal distress, accidental haemorrhage, IUGR, IUD, low birth weight, low APGAR score, NICU admissions and early neonatal death. ${ }^{7}$ Perinatal morbidity is increased due to spontaneous preterm labour or iatrogenic preterm induction.

Expectant management with temporizing treatment should be performed when possible to lengthen gestation which may be associated with enhanced perinatal survival. ${ }^{8}$ Good intensive care, close monitoring during 
labour and availability of expert NICU facilities is required for better fetal and neonatal outcome.

\section{METHODS}

We conducted a hospital based prospective case control study at Kasturba hospital from January 2014 to December 2014.

100 pregnant women with singleton pregnancy with cephalic presentation with hypertension attending the antenatal outpatient department in Kasturba Hospital were taken as cases. Hypertension during pregnancy is defined as a sustained systolic blood pressure of $140 \mathrm{~mm}$ $\mathrm{Hg}$ or more and/or a diastolic blood pressure of $90 \mathrm{mmHg}$ or more on 2 occasions at least 6 hours apart but within 7 days. ${ }^{9}$ Exclusion criteria included pregnancies complicated with diabetes mellitus, severe anaemia, heart disease, primary renal disease, collagen vascular diseases, epilepsy, patients with any presentation other than cephalic, with multiple pregnancy, Rh-negative mothers, estimated birth weight <500 grams, major fetal anomaly.

100 normal pregnancies without hypertension matched with cases at the time of admission in respect of age, parity, gestational age were taken as controls.

Fetal monitoring consisted of DFMC, FHR monitoring, NST, umbilical and cerebral Doppler. USG was done for the fetal weight, serial growth, AFI, BPP, placental location and maturity.

Treatment included rest, dietary changes, control of blood pressure by using antihypertensives (methyldopa, labetalol or nifedipine) and obstetric management. In patients of Eclampsia, treatment was given for control of $\mathrm{BP}$, control of seizures by anticonvulsants $\left(\mathrm{MgSO}_{4}\right.$ was used as the anticonvulsant of choice and Pritchard regimen was followed: $4 \mathrm{gm}$ of $25 \% \mathrm{MgSO}_{4} \mathrm{I} . \mathrm{V}$ was given slowly over 5-10 minutes and $5 \mathrm{gm}$ of $50 \% \mathrm{MgSO}_{4}$ I.M was given into each buttock followed by $5 \mathrm{gm} 50 \%$ $\mathrm{MgSO}_{4}$ I.M 4hrly in alternate buttock) and control of complications. Ultimately pregnancy was terminated and delivery was conducted.

In mild preeclampsia and gestational hypertension termination of pregnancy was done by inducing labour at 37 weeks as at this gestational age, the maternal and fetal risks during expectant management clearly outweigh potential benefits to the fetus. In patients $<37$ weeks of gestation, termination of pregnancy was warranted only if maternal condition deteriorated or if there was fetal compromise.

Pregnancy was terminated by LSCS for urgent termination for maternal sake as in acute fulminating preeclampsia and eclampsia when cervixes was not ripe and also for fetal sake when fetus was in jeopardy as indicated by deranged Doppler studies (reverse diastolic flow), severe IUGR, meconium staining of liquor or fetal distress.

The neonate was followed up till 1 week and fetal outcome was analysed in terms of number of Live births/ IUD, Maturity(term/preterm), Birth weight, Apgar score, NICU admissions and early neonatal death.

Collected data was coded into variables, entered into statistical software and analysed using SPSS version 16. Tests of significance like chi-square and Fisher's exact test were used when suitable. Multiple logistic regressions were used to calculate adjusted odd's ratio.

\section{RESULTS}

As many as 6 cases with hypertensive disorder of pregnancy had intrauterine death of fetus of which 5 deaths occurred in women with preeclampsia and only 1 in patient with gestational hypertension. In the control group, 2 mothers had intrauterine death of fetus. The difference was statistically not significant $(\mathrm{p}=0.279)$ (Table 1).

Table 1: Fetal outcome at birth among study subjects.

\begin{tabular}{|lll|}
\hline Outcome & $\begin{array}{l}\text { Cases }(\mathrm{n}=100) \\
\text { No. }(\%)\end{array}$ & $\begin{array}{l}\text { Controls }(\mathrm{n}=100) \\
\text { No. }(\%)\end{array}$ \\
\hline Live birth & $94(94)$ & $98(98)$ \\
\hline Intrauterine death & $06(06)$ & $02(02)$ \\
\hline Total & 100 & 100 \\
\hline
\end{tabular}

$\left(\chi^{2}=2.083, \mathrm{p}=0.279\right)$

Among 98 cases, 26 mothers had preterm babies whereas $73.5 \%$ women delivered babies at term. In controls only $9 \%$ women had preterm delivery. This difference was found to be statistically significant $(\mathrm{p}=0.001)$ (Table 2).

Table 2: Maturity at birth among study subjects.

\begin{tabular}{|lll|}
\hline $\begin{array}{l}\text { Maturity } \\
\text { at birth }\end{array}$ & $\begin{array}{l}\text { Cases }(\mathrm{n}=98) \\
\text { No. }(\%)\end{array}$ & $\begin{array}{l}\text { Controls }(\mathrm{n}=100) \\
\text { No. }(\%)\end{array}$ \\
\hline Term & $\mathbf{7 2 ( 7 3 . 5 )}$ & $91(91)$ \\
\hline Preterm & $26(26.5)$ & $09(09)$ \\
\hline Total & $98(100)$ & $100(100)$ \\
\hline
\end{tabular}

Table 3: Fetal weight in grams at birth of babies delivered to study subjects.

\begin{tabular}{|lll|}
\hline Fetal weight (kg) & $\begin{array}{l}\text { Cases } \\
\text { No. }(\%)\end{array}$ & $\begin{array}{l}\text { Controls } \\
\text { No. }(\%)\end{array}$ \\
\hline$<1500$ & $06(6.1)$ & $02(02)$ \\
\hline $1500-2500$ & $25(25.5)$ & $13(13)$ \\
\hline$>2500$ & $67(68.4)$ & $85(85)$ \\
\hline Total & $98(100)$ & $100(100)$ \\
\hline
\end{tabular}

$\left(\chi^{2}=9.921, p=0.012\right)$

Majority of cases $(68.4 \%)$ delivered babies having birth weight $>2.5 \mathrm{~kg}$ while $25.5 \%$ of babies born to cases had weight between $1.5 \mathrm{~kg}-2.5 \mathrm{~kg}$. $6.1 \%$ of mothers gave birth to babies having weight $<1.5 \mathrm{~kg}$. $85 \%$ of babies born to controls weighed $>2.5 \mathrm{~kg}$ followed by $13 \%$ between 
$1.5 \mathrm{~kg}-2.5 \mathrm{~kg}$ and $2 \%$ having weight $<1.5 \mathrm{~kg}$. The difference in birth weights was found to be statistically significant $(\mathrm{p}=0.012)$. The low birth weight in cases was due to both IUGR and prematurity (Table 3 ).

Apgar score $<7$ at 5 minutes was seen in $24.5 \%$ of babies born to mothers with hypertensive disorder of pregnancy as compared to only $13 \%$ of the control babies. This difference was found to be statistically significant $(\mathrm{p}=0.03)($ Table 4)

Table 4: Apgar score at 5 minutes of babies delivered to study subjects.

\begin{tabular}{|lll|}
\hline Apgar score & $\begin{array}{l}\text { Cases }(\mathbf{n = 9 8}) \\
\text { No. }(\%)\end{array}$ & $\begin{array}{l}\text { Controls }(\mathbf{n}=100) \\
\text { No. }(\%)\end{array}$ \\
\hline$<7$ & $24(24.5)$ & $13(13)$ \\
\hline$>7$ & $74(75.5)$ & $87(87)$ \\
\hline Total & $98(100)$ & $100(100)$ \\
\hline
\end{tabular}

$\left(\chi^{2}=4.30, \mathrm{p}=0.045\right)$

Of the 94 live births in cases with hypertension, 24 $(25.5 \%)$ were admitted in NICU. 4 (4.3\%) babies out of these 24 NICU admissions had early neonatal death. Of the 98 live births in controls, only 11 were admitted in NICU and discharged to mother side. There was no case of early neonatal death among controls. The difference in the rate of NICU admission in cases and controls was statistically significant $(\mathrm{p}=0.014)$ (Table 5).

Table 5: Neonatal outcome of live babies delivered to study subjects.

\begin{tabular}{|lll|l|}
\hline S no. & Neonatal outcome & $\begin{array}{l}\text { Cases } \\
\text { No. }(\%)\end{array}$ & $\begin{array}{l}\text { Controls } \\
\text { No. }(\%)\end{array}$ \\
\hline 1 & No complication & $70(74.5)$ & $87(88.8)$ \\
\hline 2 & NICU admission & $24(25.5)$ & $11(11.2)$ \\
\hline & Total & $94(100)$ & $98(100)$ \\
\hline
\end{tabular}

Of these 24 babies of cases admitted in NICU, 17 were admitted due to low birth weight (12 of them also had respiratory distress) followed by 7 due to MSL and respiratory distress. Duration of stay was less than 48 hours in 7 babies, less than or equal to a week in 12 babies and more than a week in 5 babies. During their NICU stay 5 babies were diagnosed to have sepsis, 4 were diagnosed to have hyperbilirubinemia, 3 were diagnosed to have hypoglycemia and one baby was diagnosed to have necrotizing enterocolitis. Majority of these morbidities occurred in preterm low birth weight babies.

Of the 4 early neonatal deaths that in NICU, 3 occurred due to very low birth weight and respiratory distress and 1 due to meconium aspiration syndrome and respiratory distress. All 4 were having severe respiratory distress and were put on ventilator but could not be revived.
Perinatal mortality was $10 \%$ (6 IUD+4 early neonatal deaths) in our study.

\section{DISCUSSION}

\section{Fetal outcome among study subjects}

Out of all the cases, 6 mothers had intrauterine death of babies. Out of these 6 mothers, 4 presented with intra uterine death of babies and 2 intrauterine death of babies resulted due to maternal mortality. All the other cases delivered live babies. In controls, 2 mothers had intrauterine death of baby. This difference was not statistically significant. In a study done by Pawar DS et al, $13.68 \%$ cases had IUD. ${ }^{10}$ Of the 6 of IUD, 5 occurred in preeclampsia group and 1 in gestational hypertension group. Severe and uncontrolled preeclampsia can thus lead to grave fetal consequences.

\section{Maturity at birth among study subjects}

Preterm delivery was seen in $26.53 \%$ of cases with hypertensive disorder of pregnancy whereas in controls only $9 \%$ were delivered as preterm. This difference was found to be statistically significant $(p=0.001)$. Similar rates were found by Yadav $\mathrm{S}$ et al and Bangal VB et al who found the Preterm delivery rate to be $28.8 \%$ and $37 \%$ in cases with hypertension respectively. ${ }^{11,12}$

Table 6: Studies comparing preterm delivery rate in pregnant women with hypertensive disorders of pregnancy.

\begin{tabular}{|lll|}
\hline Sr. no. & Study & Preterm delivery rate \\
\hline 1 & Yadav S et al $^{11}$ & $28.8 \%$ \\
\hline 2 & ${\text { Bangal VB et } \mathrm{al}^{12}}^{12}$ & $37 \%$ \\
\hline 3 & Our study & $26.5 \%$ \\
\hline
\end{tabular}

Of the 26 preterm deliveries in cases 20 preterm deliveries occurred in preeclampsia and eclampsia group. This indicates the greater need to terminate pregnancy in this group by induction or caesarean sections.

\section{Fetal weight in grams at birth of babies delivered to study subjects}

Birth weight $>2.5 \mathrm{~kg}$ was recorded in $68.4 \%$ of cases while $25.5 \%$ had weight between $1.5 \mathrm{~kg}-2.5 \mathrm{~kg}$ and $6.1 \%$ had weight $<1.5 \mathrm{~kg}$ as compared to controls which had $85 \%>2.5 \mathrm{~kg}, 13 \%$ between $1.5 \mathrm{~kg}-2.5 \mathrm{~kg}$ and $2 \%$ had $<1.5 \mathrm{~kg}$. This difference was found to be statistically significant $(\mathrm{p}=0.012)$. The low birth weight in cases was due to both IUGR and/or prematurity. Similarly in a study done by Sachan $\mathrm{R}$ et al, $43.70 \%$ of cases had weight $>2.5 \mathrm{~kg}, 50 \%$ had weight $1.5 \mathrm{~kg}-2.5 \mathrm{~kg}, 6.33 \%$ had weight $<1.5 \mathrm{~kg}$. ${ }^{13}$ Also Gawde A et al study had $75 \%$ cases with fetal birth weight $\geq 2.5 \mathrm{~kg}$ and $25 \%$ cases had fetal birth weight $<2.5 \mathrm{~kg} .{ }^{14}$ 
Table 7: Studies comparing fetal birth weight in pregnant women with hypertensive disorders of pregnancy.

\begin{tabular}{|llll|}
\hline Sr. No. & Study & $\geq 2.5 \mathrm{~kg}$ & $<2.5 \mathrm{~kg}$ \\
\hline 1 & Sachan $\mathrm{R} \mathrm{et} \mathrm{al}^{13}$ & $43.7 \%$ & $56.3 \%$ \\
\hline 2 & Gawde A et al $^{14}$ & $75 \%$ & $25 \%$ \\
\hline 3 & Our study & $68.4 \%$ & $31.6 \%$ \\
\hline
\end{tabular}

In patients with hypertensive disorder of pregnancy, the growth retardation of the fetus occurs due to decreased utero-placental blood flow and ischemia. Prematurity occurs due to iatrogenic termination of pregnancy before term.

\section{Apgar score at 5 minutes of babies delivered to study subjects}

In the current study, statistically significant $24.5 \%$ of babies of cases with hypertensive disorders of pregnancy had Apgar score $<7$ at 5 minutes after birth as compared to $13 \%$ of control babies with Apgar $<7(\mathrm{p}=0.03)$. Similar results were found in a study by Sachan $\mathrm{R}$ et al where $16.90 \%$ of babies had Apgar $<7$ while in a study done by Doddamani $\mathrm{G} B$ et al at Bagalkot found that $38.6 \%$ of babies had Apgar $<7$. $^{13,15}$

Table 8: Studies comparing APGAR score at 5 minutes of birth of babies delivered to pregnant women with hypertensive disorders of pregnancy.

\begin{tabular}{|lll|}
\hline Sr. No. & Study & Apgar score $<7$ \\
\hline 1 & Sachan R et al & $16.9 \%$ \\
\hline 2 & Doddamani GB et al & 15 \\
\hline 3 & Our study & $38.6 \%$ \\
\hline
\end{tabular}

Fetal hypoxia at birth, diagnosed by Apgar score $<7$ is the most important and most common fetal complication occurring at birth in hypertensive disorders of pregnancy. This is due to decreased utero-placental blood flow and ischemia in cases with hypertensive disorder of pregnancy and greater rates of induction leading to increased risk of fetal distress.

\section{Neonatal outcome of babies delivered to study subjects}

In the present study, $24(25.53 \%)$ neonates born to cases were admitted in NICU whereas only $11(11.2 \%)$ of neonates born to controls were admitted in NICU. This difference was statistically significant $(\mathrm{p}=0.014) .4$ $(4.3 \%)$ neonates admitted in NICU born to cases ended up in early neonatal death while there was no early neonatal death among neonates of controls. Similar results were found by Wolde $\mathrm{Z}$ et al who observed that $22.52 \%$ of live babies required NICU admission and $9 \%$ of live babies ended up in neonatal death. ${ }^{16}$ While Pawar DS et al found that $34.6 \%$ of live babies born to cases with hypertensive disorder of pregnancy required NICU admission and $9.88 \%$ of live babies ended up in neonatal death. $^{10}$

Table 9: Studies comparing NICU admissions and early neonatal death in babies born to women with hypertensive disorders of pregnancy.

\begin{tabular}{|llll|}
\hline $\begin{array}{l}\text { Sr. } \\
\text { No. }\end{array}$ & Study & $\begin{array}{l}\text { NICU } \\
\text { admission }\end{array}$ & $\begin{array}{l}\text { Early neonatal } \\
\text { death }\end{array}$ \\
\hline 1 & Wolde Z et al & $22.5 \%$ & $9 \%$ \\
\hline 2 & $\begin{array}{l}\text { Pawar DS et } \\
\text { al }^{10}\end{array}$ & $34.6 \%$ & $9.88 \%$ \\
\hline 3 & Our study & $25.5 \%$ & $4.3 \%$ \\
\hline
\end{tabular}

Of the 4 early neonatal deaths that occurred in NICU, 3 occurred due to very low birth weight and respiratory distress and 1 occurred due to meconium aspiration syndrome and respiratory distress. All 4 were having severe respiratory distress and were put on ventilator but could not be revived.

Perinatal mortality was $10 \%$ (6 IUD+4 early neonatal deaths) in our study. Similarly in a study done by Yadav $\mathrm{S}$ et al perinatal mortality was $14.8 \%$. $^{11}$

Chronic uteroplacental insufficiency in hypertensive disorders of pregnancy leads to IUGR, preterm delivery and fetal hypoxia. Also high rates of preterm termination of pregnancy for feto-maternal sake in hypertensive mothers results in preterm babies. Thus low birth weight due to prematurity/IUGR and fetal hypoxia are the main reasons for NICU admissions and early neonatal death in babies born to mothers with hypertensive disorders of pregnancy.

\section{CONCLUSION}

Pregnancies complicated with hypertension are associated with adverse fetal and neonatal outcome in terms of prevalence of intrauterine growth restriction, prematurity, low birth weight, low APGAR score at birth, early neonatal death, high rates of admission to NICU and the need for resuscitation. Perinatal morbidity is increased due to spontaneous preterm labour or iatrogenic preterm induction. Low birth weight due to prematurity/IUGR and fetal hypoxia are the main reasons for NICU admissions and early neonatal death in babies born to mothers with hypertensive disorders of pregnancy.

Expectant management with temporizing treatment should be performed to lengthen gestation which may be associated with enhanced perinatal survival. Good intensive care, close monitoring during labor, judicious timing of delivery and NICU facilities is required for better fetal and neonatal outcome in these cases. 


\section{ACKNOWLEDGEMENTS}

At the outset, words fall shorts to express my profound and sincere gratitude to my honourable guide, Dr. Mohini Paul, Senior specialist, Department of Obstetrics and Gynaecology, for her invaluable guidance and support for this dissertation. She has been a teacher, advisor, mentor and friend. She inculcated in me the scientific culture and temperament that is needed in clinical research. She was available at all hours and was a constant source of inspiration and encouragement. Without her meticulous correction and constant supervision I would have never been able to materialize this work. Words are not enough to express my gratitude to her.

I utilize this opportunity to thank Dr. Leela Pant, the Medical Superintendent and Dean of this institution for allowing me to conduct this study, functional help and guidance. Dr. Gurcharan Kaur, Head of the Department, Obstetrics and Gynaecology and Dr. Sangita Nangia Ajmani for providing constant encouragement and valuable guidance.

I am extremely grateful to my family, friends and god for the blessings they bestowed upon me.

\section{Funding: No funding sources}

Conflict of interest: None declared

Ethical approval: The study was approved by the Institutional Ethics Committee

\section{REFERENCES}

1. Shah A, Fawole B, M'Imunya JM, Amokrane F, Nafiou I, Wolomby JJ, et al. Cesarean delivery outcomes from the WHO global survey on maternal and perinatal health in Africa. International Journal of Gynecology and Obstetrics. 2009;107(3):191-7.

2. McClure EM, Saleem S, Pasha O, Goldenberg RL. Stillbirth in developing countries: a review of causes, risk factors and prevention strategies. Journal of Maternal-Fetal and Neonatal Medicine. 2009;22(3):183-90.

3. Prakash J, Pandey LK, Singh AK, Kar B. Hypertension in pregnancy: hospital based study. J Assoc Physicians India. 2006;54:273-8.

4. Hutter D, Kingdom J, Jaeggi E. Causes and Mechanisms of Intrauterine Hypoxia and Its Impact on the Fetal Cardiovascular System: A Review. International Journal of Pediatrics. 2010;2010:1-9.

5. Backes CH, Markham K, Moorehead P, Cordero L, Nankervis CA, Giannone PJ. Maternal Preeclampsia and Neonatal Outcomes. Journal of Pregnancy. 2011;2011:1-7.

6. Hofmeyr GJ, Belfort M. Proteinuria as a predictor of complications of pre-eclampsia. BMC Medicine. 2009;7:11.

7. Bhide A, Arulkumaran S, Damania KR, Daftary SN. Arias' practical guide to high-risk pregnancy and delivery a south Asian perspective. $4^{\text {th }}$ edition. Haryana: Reed Elsevier India Private Limited; Chapter 13, Hypertensive disorders in pregnancy; 2015:185-232.

8. Hassan M, Choudhury F, Begum M, Rahman H, Akhter S. Immediate Perinatal Outcome of Neonates with Maternal Hypertensive Disorders in Pregnancy. J Nepal Paediatr Soc. 2013;33(3):190-5.

9. Cunningham FG, Levano KJ, Bloom SL, Hauth JC, Rouse DJ, Spong CY. Williams Obstetrics. 23rd edition. New York: Mc Graw Hill publishing division; Chapter 34, Pregnancy Hypertension; 2010:706-56.

10. Pawar DS. Perinatal outcome in cases of pih (MS thesis). Ahemdabad: Gujarat University. 2012.

11. Yadav S, Saxena U, Yadav R, Gupta S. Hypertensive disorders of pregnancy and maternal and foetal outcome: a case controlled study. J Indian Med Assoc. 1997;95(10):548-51.

12. Bangal VB. Purushottam A. Giri PA, Mahajan AS. Maternal and foetal outcome in pregnancy induced hypertension: a study from rural tertiary care teaching hospital in India. International Journal of Biomedical Research. 2011;2(12):595-9.

13. Sachan R, Patel ML, Sachan P, Gaurav A, Singh M, Bansal B. Outcomes in hypertensive disorders of pregnancy in the north Indian population. Int $\mathbf{J}$ Womens Health. 2013;5:101-8.

14. Gawde A, Bhosale UT. A study of maternal and perinatal outcome in preeclampsia. International Journal of Recent Trends in Science and Technology. 2014;10(2):267-70.

15. Doddamani GB, Doddamani UG. Perinatal outcome in pre-eclampsia: A prospective study. Sch. J. App. Med. Sci. 2014;2(1C):291-3.

16. Wolde Z, Segni H, Woldie M. Hypertensive disorders of pregnancy in Jimma University specialized hospital. Ethiop J Health Sci. 2011;21(3):147-54.

Cite this article as: Vats K, Paul M. Study of fetal outcome in hypertensive disorders of pregnancy in a tertiary care maternity hospital of Delhi. Int J Reprod Contracept Obstet Gynecol 2016;5:3773-7. 